\title{
Is Vitamin D deficiency an endangerment for Fracture?
}

\author{
Ram GG. ${ }^{1 *}$, Raman R. ${ }^{2}$ \\ DOI: https://doi.org/10.17511/ijoso.2020.i01.06 \\ 1* Ganesan G. Ram, Associate Professor, Department of Orthopaedics, Velammal Medical College, Madurai, Tamil Nadu, India. \\ 2 Ravi Raman, Professor, Department of Orthopaedics, Velammal Medical College, Madurai, Tamil Nadu, India.
}

Introduction: The incidence of fragility hip fracture is on a step increase. Vitamin $D$ is essential for the growth and development of the bone. The decrease in the exposure to sun's radiation leads to this deficiency causing a global threat. There were many studies pointing towards Vitamin $D$ deficiency as a risk factor for fracture. However, the relationship between serum Vitamin $D$ and bone mineral density (BMD) in the senile osteoporotic fracture is still unclear. The aim of this study is to find out whether Vitamin D deficiency is a risk factor for fragility fracture. Method: It is a prospective study done at Sri Ramachandra Medical College Chennai and Velammal Medical college Madurai between Jan 2017 to Dec 2019. The inclusion criteria were male patients age more than seventy and female patients more than sixty presented with fragility hip fractures. The group I was the cases, patients with hip fractures. The group II was the age and gender-matched control. All the patients included in the study underwent both Vitamin D $25 \mathrm{OH}$ and Dexa scan. The current study had 56 patients in group I as cases and 54 patients in group II as control. Results: The mean value of vitamin D $25 \mathrm{OH}$ in fracture patient group I was 19.85 and the age and gender-matched control group was 26.09. The current study had totally seventy-nine patients in the study who were either Vitamin $D$ deficient or insufficient. The present study had 16 cases patient and 15 controls who were having sufficient level vitamin D. Conclusion: Vitamin D has no role in fracture prevention and certainly Vitamin $D$ deficiency is not an endangerment for fractures.

Keywords: Vitamin D, Fracture, Fragility, Osteoporosis, DEXA

\section{Corresponding Author}

Ganesan G. Ram, Associate Professor, Department of Orthopaedics, Velammal Medical College, Madurai, Tamil Nadu, India.

Email: ganesangram@yahoo.com
How to Cite this Article Ram GG, Raman R. Is Vitamin D deficiency an endangerment for Fracture?. Surgical Review Int J Surg Trauma Orthoped. 2020;6(1):35-39. Available From https://surgical.medresearch.in/index.php/ijoso/artic le/view/141
To Browse

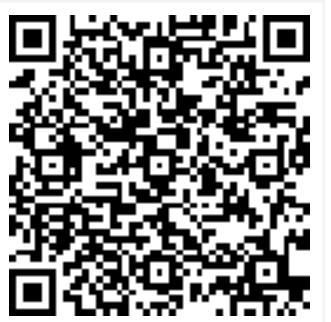

\section{Introduction}

The incidence of fragility hip fracture is on a step increase. Exact statistics in our country are not known but the incidence is extremely high. The condition is associated with very high morbidity and mortality and has a tremendous impact on both the health care Manuscript Received 18-01-2020

Conflict of Interest No
System and society in general $[1,2]$. The inhospital mortality following a hip fracture ranges anywhere between $10-15 \%$ [3]. The social, as well as the economic burden of hip fracture, is relied upon to increment in the next 50 years because of the older population in developing and underdeveloped countries. Vitamin $D$ is essential for the growth and 
Development of the bone. The decrease in the exposure to sun's radiation leads to this deficiency causing a global threat.

There were many studies pointing towards Vitamin D deficiency as a risk factor for fracture. However, the relationship between serum Vitamin $D$ and bone mineral density (BMD) in the senile osteoporotic fracture is still unclear [4]. Vitamin D deficiency was associated with an increased risk of falls and a higher propensity for hip fractures [5]. In patients with a hip fracture, the main cause for a secondary bone loss was mainly related to calcium and vitamin D homeostasis [6].

The decrease in muscle endurance and mineralization deficiency due to vitamin $D$ deficiency is the main cause of these fragility hip fractures. The incidence of hip fracture is high amongst the vitamin $D$ deficient population while comparing to the normal people [7]. There were conflicting opinions, results of researches and scientific community regarding the role of Vitamin D deficiency and hip fracture incidence. For this proceeding with uncertainty and vulnerability and the requirement for firm proof in regards to Vitamin $D$ deficiency and hip fracture is the need of the hour. The aim of this study is to find out whether Vitamin $\mathrm{D}$ deficiency is a risk factor for fragility fracture.

\section{Materials and Method}

Type of study: It is a prospective study done at Sri Ramachandra Medical College Chennai and Velammal Medical college Madurai between January 2017 to December 2019.

Inclusion criteria: The inclusion criteria were male patients age more than seventy and female patients more than sixty presented with fragility hip fractures.

Exclusion criteria: If patients were having fragility fractures of wrist or spine they were excluded. Other exclusion criteria were patients who were taking Vitamin D supplements, underwent previous hip surgery, chronic or acute kidney disease, liver failure, tumor and malignancy, hyperthyroidism or hyperparathyroidism and any drugs that can affect bone metabolism [8].

Sample size: The sample size was calculated by the probability sampling method and found to be fifty. The study contains two groups. The group I was the cases, patients with hip fractures. The group II was the age and gender-matched control.
All the patients included in the study underwent both Vitamin D $25 \mathrm{OH}$ and Dexa scan [9]. The current had 56 patients in group I as cases and 54 patients in group II as control. All the patients who had fracture included in the study within 48 hours of fracture occurrence and all the investigations were done within 48 hours following the fracture.

Data analysis: The collected data were analyzed with IBM.SPSS statistics software 23.0 Version. To describe the data descriptive statistics frequency analysis, percentage analysis was used for categorical variables and the Mean and S.D were used for continuous variables. To find the significance in the categorical data Chi-Square test was used. In all the above statistical tools the probability value 0.05 is considered as significant level.

\section{Results}

The mean value of vitamin D $250 \mathrm{H}$ in fracture patient group I was 19.85 and the age and gendermatched control group was 26.09 as tabulated in Table 1. A total of seventy-nine patients in the study who were either Vitamin $D$ deficient or insufficient. The present study had 16 cases of the patient and 15 controls who were having sufficient level vitamin $D$ as per Table 3. When the vitamin D levels with DEXA scan were equated in Table 5 , it was observed that 16 osteopenic and osteoporotic patients having normal level Vitamin D3.

Table-1: Mean value of Vitamin D $250 H$ in the fracture group and normal patients.

\begin{tabular}{|l|l|l|l|}
\hline \multicolumn{1}{|c|}{ Group } & \multicolumn{1}{c|}{ Number } & \multicolumn{1}{c|}{ Mean } & \multicolumn{1}{c|}{ Std. Deviation } \\
\hline I-Case & 56 & 19.85 & 13.24 \\
\hline II-Control & 54 & 26.09 & 29.07 \\
\hline
\end{tabular}

Table-2: Independent sample test for fracture and Vitamin D 25 OH.

\begin{tabular}{|l|l|l|l|l|l|}
\hline \multirow{2}{*}{} & \multicolumn{4}{|c|}{ t-test for Equality of Means } \\
\cline { 2 - 6 } & $t$ & df & Sig. (2-tailed) & Mean Difference & Std. Error Difference \\
\hline Vit D 25 OH & 1.457 & 108 & 0.148 & 6.2409 & 4.2826 \\
\hline
\end{tabular}

\section{Discussion}

Vitamin D deficiency is the major risk factor causing Osteoporosis. The decrease in the exposure to sunlight causing osteoporosis has become a global problem. Public, in general, was convinced by different investigations and television commercials that Vitamin D is the cure for osteoporosis and fracture. This reasoning is suggestive of the enthusiasm that upheld the broad utilization of 
Vitamin A, Vitamin C, and Vitamin E years back, and those nutrient preliminaries later end up being clinically negative. The primary source of Vitamin D is the light emitted from the sun which makes the human skin produce Vitamin D3, and next source is the food consumed that contains Vitamin D2 which could form $25(\mathrm{OH}) \mathrm{D} 3$ and $25(\mathrm{OH}) \mathrm{D} 2$ after treated by 25 hydroxylases in the liver.

Moreover, they can form 1,25(OH)2D3 and $1,25(\mathrm{OH}) 2 \mathrm{D} 2$ under the effect of 1 a hydroxylase in the kidney [10]. 1,25(OH)2D3 is the highest concentration metabolite of vitamin $D$ with half-life at $2 \sim 3$ weeks.

It is not subject to the regulation of calcium, phosphorus, and PTH [11]. Vitamin D deficiency is a major health issue in elderly patients [12] Monitoring vitamin $\mathrm{D}$ level is of great significance for osteoporosis prevention. 25-Hydroxyvitamin-D $[25(\mathrm{OH}) \mathrm{D}]$ is considered as the best indicator to evaluate vitamin D level $[13,14]$. Food and Drug Administration confirmed that serum $25(\mathrm{OH}) \mathrm{D}$ is an effective index to test vitamin $D$ level.

Table-3: Vitamin D3 values in the cases and the controls.

\begin{tabular}{|l|l|l|l|}
\hline \multirow{2}{*}{ Vit D3 values $\mathbf{n g} / \mathrm{ml}$} & \multicolumn{2}{c|}{ Groups } & \multirow{2}{*}{ Total } \\
\cline { 2 - 3 } & Cases & Controls & \\
\hline Deficient $0-10$ & 12 & 7 & 19 \\
\hline Insufficient $11-20$ & 32 & 28 & 60 \\
\hline Sufficient $>20$ & 16 & 15 & 31 \\
\hline
\end{tabular}

Table-4: Chi-square test for Vitamin D.

\begin{tabular}{|l|l|l|l|}
\hline & Value & \multicolumn{1}{c|}{ df } & Asymp. Sig. (2-sided) \\
\hline Pearson Chi-square & $0.712 \mathrm{a}$ & 2 & 0.701 \\
\hline Likelihood ratio & 0.720 & 2 & 0.698 \\
\hline Linear-by-linear association & 0.532 & 1 & 0.466 \\
\hline N of Valid cases & 110 & & \\
\hline
\end{tabular}

Table-5: Vitamin D3 values as per DEXA results.

\begin{tabular}{|l|l|l|l|l|}
\hline \multirow{2}{*}{ Vit D3 values $\mathbf{n g} / \mathrm{ml}$} & \multicolumn{3}{|c|}{ DEXA scan } & \multirow{2}{*}{ Total } \\
\cline { 2 - 5 } & Normal & Osteopenia & Osteoporosis & \\
\hline Deficient $0-10$ & 7 & 5 & 7 & 19 \\
\hline Insufficient $11-20$ & 28 & 11 & 21 & 60 \\
\hline Sufficient $>20$ & 15 & 4 & 12 & 31 \\
\hline
\end{tabular}

Table 6: Chi-square test as per DEXA.

\begin{tabular}{|l|l|l|l|}
\hline & Value & \multicolumn{1}{c|}{ df } & Asymp. Sig. (2-sided) \\
\hline Pearson Chi-square & $1.634 \mathrm{a}$ & 4 & 0.803 \\
\hline Likelihood ratio & 1.623 & 4 & 0.805 \\
\hline Linear-by-linear association & 092 & 1 & 0.762 \\
\hline N of Valid cases & 10 & & \\
\hline
\end{tabular}

Fragility Hip fractures were the most common fractures in patients presenting to the trauma center or orthopedic department. Patients with a history of hip fracture have a 2.5 -fold risk to sustain another osteoporotic fracture than in age-matched people without a previous hip fracture [15]. All national and international society guidelines on osteoporosis advocate evaluating patients with hip fractures in order to consider treatment to reduce the risk of subsequent fractures.

The decreased muscle mass and muscle strength are collectively known as sarcopenia, which was considered as a linking factor between Vitamin D deficiency and fragility fracture. There were no evidence-based studies relating independent relationship established between fragility hip fracture and Vitamin D deficiency. Also, there is a dearth of interventional studies proving Vitamin $D$ supplement improving the fragility of the bone $[16$,$] .$

Fractures are the dreaded complication of osteoporosis. The mortality and morbidity increase once the osteoporotic individual sustains a fracture. There is an ongoing debate amongst the Orthopaedic fraternity regarding the role of Vitamin D for the prevention of fracture. Even though there are papers supporting both ends of this burning issue there is no clear-cut judgment. Nutrient D the daylight nutrient - is the most loved and is accepted to have the most demonstrated advantages. Governments, including the UK government, have said that the proof for nutrient D's medical advantages is overpowering to the point that each grown-up should accept it as an enhancement for at any rate a half year of the year. The possible benefit of taking vitamin $D$ supplements is that it helps prevent osteoporosis, thereby decreasing bone fractures. However, there is currently not enough evidence to say that Vitamin $D$ plays a pivotal role in the prevention of fractures.

From Tables 1 and 2, it is clearly evident that the mean Vitamin $D$ values in the fracture group and control group are not statistically significant. The present study result was similar to the results of Bolland et al whose meta-analysis clearly nails that vitamin $D$ has no role in fracture prevention. Vitamin D supplementation does not prevent fractures or falls or have clinically meaningful effects on bone mineral density $[17,18]$. The current study had sixteen patients with sufficient vitamin $D$ levels out of fifty-six patients who had fractures and fifteen patients having sufficient level out of fifty- 
Four persons in the control group. Similarly, the current study had 16 patients in the fracture group having sufficient Vitamin D value but Dexa revealed them having either osteopenic/Osteoporosis. When the classification of Vitamin D deficiency levels to both Dexa scan and Cases and control in the present study were equated, a satisfactory result supporting the Vitamin $D$ depletion causing fracture was not observed. Tables 4 and 6 statistically imply that Vitamin $D$ has no role in fracture prevention and it is also not linearly proportional to Dexa.

\section{Limitations}

The limitations of the studies are that the study population is only confined to Tamil Nadu only when the magnitude of this problem is worldwide and the sample size is small for this global issue. The subset of population taken into the study is the elderly population who also has various other reasons for fall and fracture like decreased visual acuity so that just supplementing the whole study population with vitamin $D$ may not significantly reduce falls. Correspondingly for osteoporotic fracture, there are different skeletal and non-skeletal elements that impact fracture hazard, and nutrient $D$ supplementation may not be useful if non-Vitamin D-responsive hazard factors are the prevalent cause for fracture.

\section{Conclusion}

The present study evidences that Vitamin D does not play a part in fracture prediction; also, it is not proportionate to the Dexa scan. Vitamin $D$ has no role in fracture prevention and certainly, Vitamin $D$ deficiency is not an endangerment for fractures.

\section{What does the study add to the existing Knowledge?}

Vitamin D was considered as a divine medicine for osteoporosis and prevent fracture by most of the physician and patients. This study proves that Vitamin $D$ is only a myth and it has no role in fracture prevention and fall.

\section{Author's contribution}

Dr. Ganesan G Ram: Study design, Ethical approval, Manuscript preparation, Patient selection, Data Analysis.

Dr. Ravi Raman: Data Analysis.

\section{Reference}

01. Papaioannou A, Morin S, Cheung AM, Atkinson $S$, Brown JP, Feldman S, Hanley DA, Hodsman A, Jamal SA, Kaiser SM, Kvern B. 2010 clinical practice guidelines for the diagnosis and management of osteoporosis in Canadasummary. CMAJ. 2010;182(17)1864-1873.

doi: [Article:https://doi.org/10.1503/cmaj.100771] [Crossref]

02. Tenenhouse A, Joseph L, Kreiger N, Poliquin S, Murray TM, Blondeau $L$, et al. CaMos Research Group, Estimation of the prevalence of low bone density in Canadian women and men using a population-specific DXA reference standard- the Canadian Multicentre Osteoporosis Study (CaMos). Osteoporos Int. 2000;11(10)897-904. doi:

[Article:https://doi.org/10.1007/s001980070050] [Crossref]

03. Ramason R, Selvaganapathi N, Ismail NH, Wong WC, Rajamoney GN, Chong MS. Prevalence of vitamin d deficiency in patients with hip fracture seen in an orthogeriatric service in sunny Singapore. Geriatr Orthop Surg Rehabil. 2014;5(2)82-86.

doi:

[Article:https://doi.org/10.1177/2151458514528952] [Crossref]

04. Ram GG, Govardhan P. In-Hospital Mortality following Proximal Femur Fractures in Elderly Population. Surg J. 2019;5(02)e53-e56.

doi: [Article:https://doi.org/10.1055/s-00391692995][Crossref]

05. Bischoff-Ferrari HA, Giovannucci E, Willett WC, Dietrich T, Dawson-Hughes B. Estimation of optimal serum concentrations of 25hydroxyvitamin $D$ for multiple health outcomes. Am J Clin Nutr. 2006;84(1)18-28.

doi: [Article:https://doi.org/10.1093/ajcn/84.1.18] [Crossref]

06. Souberbielle JC, Body JJ, Lappe JM, Plebani M, Shoenfeld $Y$, Wang TJ, et al. Vitamin $D$ and musculoskeletal health, cardiovascular disease, autoimmunity, and cancer- Recommendations for clinical practice. Autoimmunity Rev. 2010;9(11)709-715.

doi:

[Article:https://doi.org/10.1016/j.autrev.2010.06.009 ][Crossref] 
07. Behrouzi A, Hejazi $H$, Kamali A, Hadi $H$. Investigation of the outcome of patients with hip fractures using vitamin D3. Eur J Transl Myol. $2018 ; 28(3) 7372$.

doi:

[Article:https://dx.doi.org/10.4081\%2Fejtm.2018.73 72][Crossref]

08. Ram GG, Jambu N. Urinary N-telopeptide-A diagnostic Test or A Screening Test?. Int J Res Pharmaceut Sci. 2019;10(2)1298-1301. doi:

[Article:https://doi.org/10.26452/ijrps.v10i2.424] [Crossref]

09. Solomon DH, Finkelstein JS, Katz JH, Mogun $H$, Avorn J. Underuse of osteoporosis medications in elderly patients with fractures. Am J Med. 2003;115(5)398-400.

doi: [Article:https://doi.org/10.1016/s00029343(03)00357-7][Crossref]

10. Ganesan GR, Vijayaraghavan PV. Urinary Ntelopeptide- The New Diagnostic Test for Osteoporosis. Surg J. 2019;5(1)e1-e4.

doi: [Article:https://doi.org/10.1055/s-00381677483][Crossref]

11. He W, Liu M, Huang X, Qing Z, Gao W. The influence of vitamin $D$ receptor genetic variants on bone mineral density and osteoporosis in Chinese postmenopausal women. Disease markers. 2015.

doi: [Article:https://doi.org/10.1155/2015/760313] [Crossref]

12. Hossein-nezhad A, Holick MF. Vitamin D for health- a global perspective. In Mayo Clinic Proc. $2013 ; 8(7) 720-755$.

doi:

[Article:https://doi.org/10.1016/j.mayocp.2013.05.0 11][Crossref]

13. Holick MF, Binkley NC, Bischoff-Ferrari HA, Gordon CM, Hanley DA, Heaney RP, et al. Evaluation, treatment, and prevention of vitamin D deficiency- an Endocrine Society clinical practice guideline. J Clini Endocrinol Metabol. 2011;96(7)1911-1930.

doi: [Article:https://doi.org/10.1210/jc.2011-0385] [Crossref]

14. Wong YY, Flicker L. Hypovitaminosis $D$ and frailty- Epiphenomenon or causal?. Maturitas. 2015;82(4)328-335.

doi:[Article:https://doi.org/10.1016/j.maturitas.

2015.07.027][Crossref]
15. Mosali P, Bernard L, Wajed J, Mohamed Z, Ewang $M$, Moore $A$, et al. Vitamin D status and parathyroid hormone concentrations influence the skeletal response to zoledronate and denosumab. Calcif Tissue Int. 2014;94(5)553559.

doi: [Article:https://doi.org/10.1007/s00223-0149840-0][Crossref]

16. Piscitelli $P$, Iolascon $G$, Gimigliano $F$, Muratore $M$, Camboa $\mathrm{P}$, Borgia $\mathrm{O}$, et al. Incidence and costs of hip fractures compared to acute myocardial infarction in the Italian population- a 4-year survey. Osteoporosis Int. 2007;18(2)211-219.

doi: [Article:https://doi.org/10.1007/s00198-0060224-9][Crossref]

17. Gallagher JC. Vitamin D and bone density, fractures, and falls- the end of the story?. Lancet Diabetes Endocrinol. 2018;6(11)834835.

doi: [Article:https://doi.org/10.1016/s22138587(18)30269-9][Crossref]

18. Bolland MJ, Grey A, Avenell A. Effects of vitamin $D$ supplementation on musculoskeletal health- a systematic review, meta-analysis, and trial sequential analysis. The Lancet Diabetes Endocrinol. 2018;6(11)847-858.

doi: [Article:https://doi.org/10.1016/s22138587(18)30265-1][Crossref] 